\title{
Meta Analisis Pengaruh Cooperative Learning terhadap Prestasi Belajar Matematika
}

\author{
Muhammad Khusni Amin ${ }^{1, *}$, Isnani ${ }^{2}$, Paridjo ${ }^{3}$ \\ 1,2,3 Universitas Pancasakti Tegal \\ *khusniamin7@gmail.com
}

\begin{tabular}{|l|l|l|l|}
\hline Received : 20-09-2020 & Revised: 05-11-2020 & Accepted: $10-11-2020$ & Published: 05-12-2020 \\
\hline
\end{tabular}

\begin{abstract}
ABSTRAK
Seiring dengan banyaknya penelitian skripsi yang membahas topik atau kajian yang sama, perlu untuk mengkaji ulang beberapa penelitian yang sejenis. Salah satu topik yang sering dibahas dalam skripsi adalah cooperative learning. Penelitian ini bertujuan untuk mendeskripsikan besar pengaruh cooperative learning terhadap prestasi belajar matematika secara keseluruhan, berdasarkan tipe yang digunakan, berdasarkan jenjang pendidikan, berdasarkan media pembelajaran, dan berdasarkan materi yang diajarkan. Metode penelitian yang digunakan adalah kuantitatif deskriptif. Populasi dalam penelitian ini adalah skripsi mahasiswa Pendidikan Matematika Universitas Pancasakti Tegal tahun 2016 sampai 2019. Teknik sampling menggunakan purposive sampling dan didapatkan 44 skripsi yang sesuai kriteria. Teknik analisis data menggunakan teknik analisis besaran pengaruh Cohen's $d$ effect size. Hasil analisis menunjukkan, secara keseluruhan cooperative learning mampu meningkatkan prestasi belajar matematika dengan effect size sebesar 0,73 yang termasuk kategori sedang. Berdasarkan tipe cooperative learning, dari delapan belas tipe yang digunakan dalam penelitian mahasiswa, tipe talking stick adalah yang paling besar pengaruhnya dengan effect size sebesar 1,06 yang termasuk kategori besar. Berdasarkan jenjang pendidikan, penerapan cooperative learning pada jenjang SLTP lebih tinggi pengaruhnya dari jenjang SLTA dengan effect size sebesar 0,76 yang termasuk kategori sedang. Berdasarkan media pembelajaran, aplikasi komputer atau website menunjukkan hasil yang positif dengan effect size sebesar 0,79 yang termasuk kategori sedang. Berdasarkan materi yang diajarkan, lingkaran memberikan pengaruh paling tinggi dalam cooperative learning dengan effect size sebesar 1,07 yang termasuk kategori besar. Artinya cooperative learning tipe talking stick yang diterapkan pada jenjang SLTP dengan menggunakan media komputer atau website pada materi lingkaran mampu meningkatkan prestasi belajar matematika.
\end{abstract}

Kata Kunci: Meta Analisis, Cooperative Learning, Prestasi Belajar Matematika

\begin{abstract}
This study aims to describe effect size of cooperative learning on overall mathematics achievement, based on the type used, based on education stage, based on learning media, and based on the subject matter. The research methods used are quantitative descriptive. The population in this study ia a thesis of mathematics education students of Pancasakti Tegal University from 2016 to 2019. Sampling technique used purposive sampling and obtained 44 theses according to the criteria. Data analysis techniques use the analysis technique of Cohen's d effect size. The results of the analysis showed that overall cooperative learning was able to improve mathematics achievement with an effect size of 0,73 which include medium category. Based on the type of cooperative learning, of the eighteen types used in student research, the talking stick has the greatest influence with an effect size of 1,06 which include large category. Based on educational stage, implementation of cooperative learning in junior high school has a higher influence than senior high school with an effect size of 0,76 which include medium category. Based on learning media, computer applications or websites show positive result with an effect size of 0,79 which include medium category. Based on subject matter, circle material has the highest influence in
\end{abstract}


cooperative learning with an effect size of 1,07 which include large category. This means that cooperative learning with the talking stick type applied at junior high school using computer media on circular materials can improve mathematics learning achievement.

Keywords: Meta Analysis, Cooperative Learning, Mathematics Achievement

\section{PENDAHULUAN}

Matematika merupakan salah satu mata pelajaran yang dipelajari pada setiap jenjang pendidikan di Indonesia. Pendidikan matematika adalah ilmu dasar yang sangat berguna bagi kehidupan manusia. Hal ini dimaksudkan untuk membekali mereka dengan kemampuan berpikir logis, analitis, sistematis, kritis, kreatif, serta kemampuan dalam bekerjasama (Maskur et al., 2020; Septian, Darhim, \& Prabawanto, 2020). Permasalahannya adalah masih banyak peserta didik yang tidak suka dengan matematika dan menganggap matematika adalah pelajaran yang membosankan (Nurjanah, 2019). Keadaan ini dapat berpengaruh pada prestasi belajar peserta didik (Budiman \& Esvigi, 2017).

Prestasi belajar merupakan salah satu tolak ukur yang digunakan untuk mengetahui suatu keberhasilan dalam proses pembelajaran. Prestasi belajar adalah hasil dari suatu proses atau aktivitas sehingga menghasilkan sebuah perubahan dalam individu yaitu berupa nilai (Eliyah, Isnani, \& Utami, 2018). Menurut Cronbach (Siagian, 2015) kegunaan prestasi belajar antara lain sebagai umpan balik bagi guru dalam mengajar, untuk keperluan diagnostik, untuk keperluan bimbingan dan penyuluhan, untuk keperluan seleksi, untuk keperluan penempatan atau penjurusan, untuk menentukan isi kurikulum, dan untuk menentukan kebijakan sekolah. Prestasi belajar matematika adalah nilai yang berhasil dicapai oleh peserta didik dalam mengerjakan soal tes matematika (Isnani \& Ambarwati, 2011; Suwarman et al., 2018). Hasil PISA tahun 2018 untuk kategori matematika, Indonesia berada pada peringkat 73 dari 79 negara yang disurvei dengan skor rata-rata 379. Hal ini menunjukkan bahwa prestasi Indonesia masih tergolong rendah dibandingkan dengan negara lain.

Salah satu faktor yang menyebabkan rendahnya prestasi belajar matematika adalah pemilihan model pembelajaran yang tidak sesuai dengan kondisi peserta didik. Cooperative learning merupakan kegiatan pembelajaran yang dilakukan dengan cara berkelompok untuk dapat saling berinteraksi dan bekerjasama dalam memaksimalkan proses belajar mereka sehingga dapat meningkatkan prestasi belajarnya. Cooperative learning adalah pembelajaran yang berfokus pada penggunaan kelompok kecil peserta didik untuk bekerja sama dalam mencapai tujuan bersama (Situmeang, 2016). Karakteristik 
cooperative learning menurut Rusman (2016) yaitu pembelajaran dilakukan secara tim, didasarkan pada manajemen kooperatif, adanya kemauan untuk bekerjasama, dan keterampilan dalam bekerjasama. Tujuan cooperative learning salah satunya adalah untuk meningkatkan prestasi akademik (Hijrihani \& Wutsqa, 2015). Penelitian mengenai cooperative learning telah banyak dilakukan dan ternyata hasilnya mengungkapkan bahwa cooperative learning mampu meningkatkan prestasi belajar matematika peserta didik. Namun dari sekian banyak penelitian tersebut dilakukan dengan menerapkan tipe cooperative learning yang berbeda, jenjang pendidikan yang berbeda, media pembelajaran yang berbeda, dan materi pelajaran yang berbeda pula.

Berdasarkan hasil pengamatan di Perpustakaan Pusat Universitas Pancasakti Tegal, terdapat 80 skripsi pada rentang tahun 2016 sampai tahun 2019 yang membahas tentang cooperative learning. Seiring dengan banyaknya penelitian skripsi yang membahas topik atau kajian yang sama dengan berbagai karakteristik yang terdapat didalamnya seperti pemanfaatan cooperative learning pada jenjang pendidikan tertentu, penggunaan media pembelajaran yang berbeda, dan materi pelajaran yang diajarkan pada pokok bahasan tertentu, perlu untuk meninjau kembali penelitian-penelitian yang berhubungan atau sejenis sehingga diperoleh kesimpulan yang akurat. Salah satu metode yang dapat digunakan untuk mendapatkan hasil yang akurat dan kredibel adalah melalui metode meta analisis.

Meta analisis merupakan metode statistik untuk menggabungkan hasil kuantitatif dari beberapa penelitian untuk menghasilkan rangkuman secara keseluruhan atas pengetahuan empiris pada topik tertentu (Anadiroh, 2019). Menurut Glass (Aslikhah, 2015) meta analisis adalah analisis dari berbagai analisis atau analisis statistik dari sekumpulan besar hasil analisis dari penelitian individu dengan tujuan untuk mengintegrasikan suatu kesimpulan. Meta analisis adalah suatu bentuk penelitian kuantitatif yang menggunakan angka-angka dan metode statistik dari beberapa hasil penelitian untuk mengorganisasikan dan menggali informasi sebanyak mungkin dari data yang diperoleh sehingga mendekati kekomprehensifan (Chandra, 2011). Metode ini bertujuan untuk menjawab pertanyaan yang menyangkut masalah perbedaan antara kelompok eksperimen dengan kelompok kontrol jika didasarkan hasil-hasil penelitian yang terus bertambah dari tahun ke tahun (Prasetiyo, Yusmin, \& Hartoyo, 2014). Meta analisis menyatakan hasil-hasil penemuan kajian dengan effect size. Hal ini dilakukan untuk mengkaji kekonsistenan atau ketidakkonsistenan hasil penelitian yang disebabkan semakin banyaknya penelitian yang sejenis dan sering kali memperbesar terjadinya variasi hasil penelitian. 
Beberapa penelitian sebelumnya tentang meta analisis cooperative learning mengungkapkan bahwa prestasi belajar matematika peserta didik pada kelas yang diajar dengan cooperative learning menunjukkan hasil yang positif dan signifikan dengan ratarata effect size yang dihasilkan pada kategori sedang (Capar \& Tarim, 2015). Selain itu, dalam penelitian lainnya mengungkapkan dari 22 skripsi cooperative learning yang diteliti menunjukkan hasil yang positif dalam meningkatkan hasil belajar matematika (Prasetiyo et al., 2014). Stoner (2004), melakukan penelitian terhadap 25 studi eksperimen dan temuannya menunjukkan hasil yang positif terhadap prestasi belajar peserta didik.

Berdasarkan latar belakang tersebut maka tujuan dalam penelitian ini adalah untuk mendeskripsikan: (1) seberapa besar pengaruh cooperative learning terhadap prestasi belajar matematika secara keseluruhan; (2) seberapa besar pengaruh cooperative learning terhadap prestasi belajar matematika berdasarkan tipe yang digunakan; (3) seberapa besar pengaruh cooperative learning terhadap prestasi belajar matematika berdasarkan jenjang pendidikan; (4) seberapa besar pengaruh cooperative learning terhadap prestasi belajar matematika berdasarkan media yang digunakan; dan (5) seberapa besar pengaruh cooperative learning terhadap prestasi belajar matematika berdasarkan materi yang diajarkan.

\section{METODE PENELITIAN}

Meta analisis merupakan suatu bentuk penelitian kuantitatif karena menggunakan angka-angka dan metode statistik dari beberapa hasil penelitian untuk mengorganisasikan dan menggali informasi sebanyak mungkin dari data yang diperoleh sehingga mendekati kekomprehensifan (Chandra, 2011). Penelitian ini dilakukan dengan populasi sebanyak 243 skripsi mahasiswa pendidikan matematika Universitas Pancasakti Tegal rentang tahun 2016 sampai tahun 2019. Sampel yang diambil adalah 44 skripsi tentang cooperative learning terhadap prestasi belajar matematika melalui teknik purposive sampling. Purposive sampling adalah teknik pengambilan sampel yang berdasarkan atas suatu pertimbangan tertentu yang bertujuan agar data yang diperoleh nantinya bisa lebih representatif (Sugiyono, 2015). Teknik pengumpulan data yang digunakan dalam penelitian ini yaitu dokumentasi berupa hasil prestasi belajar kelas eksperimen dan kelas kontrol pada sampel skripsi serta data statistik lain yang diperlukan.

Coding merupakan instrumen yang penting dalam meta analisis untuk mempermudah pengumpulan dan analisis data. Instrumen dalam penelitian ini berupa lembar pemberian kode yang berisi informasi seputar judul penelitian, nama peneliti, tahun 
penelitian, tipe cooperative learning yang digunakan dalam penelitian, jenjang pendidikan subjek penelitian, media yang digunakan dalam penelitian, materi yang diajarkan dalam penelitian, desain penelitian, ukuran sampel penelitian, dan analisis data penelitian.

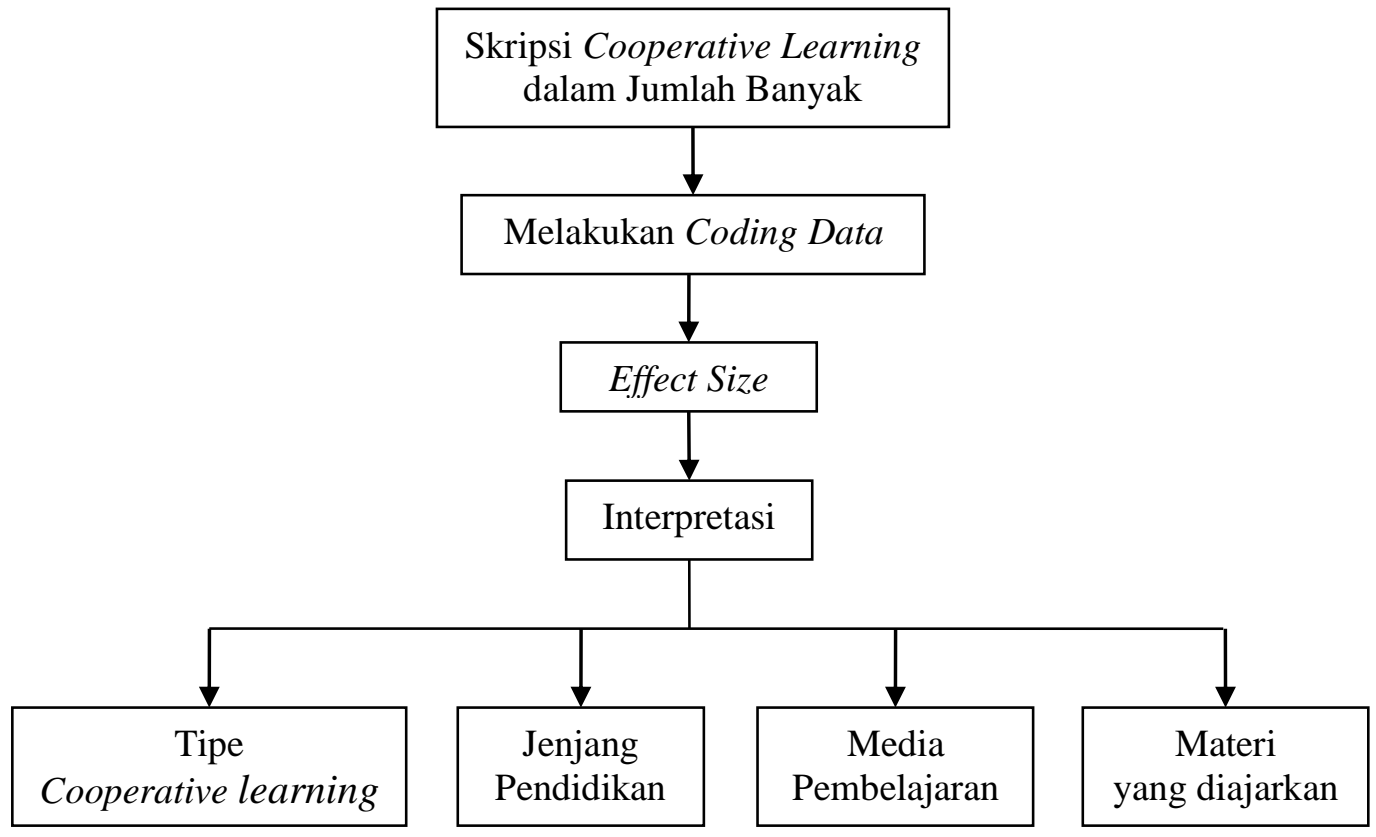

Gambar 1. Flowchart Metode Penelitian

Unit dasar studi meta analisis adalah effect size, maka untuk menjawab rumusan masalah penelitian digunakan perhitungan dengan teknik analisis besaran pengaruh atau effect size. Langkah-langkah analisis data adalah (1) identifikasi rerata (mean) dan standar deviasi dari data pada kelas eksperimen dan kelas kontrol untuk setiap subjek penelitian, (2) penghitungan effect size dengan rumus Cohen's (Glass \& Smith, 2012) berdasarkan rerata dan standar deviasi yang telah diketahui, yaitu mencari besarnya effect size (ES) dengan cara membagi selisih rerata kelas eksperimen dengan rerata kelas kontrol, dengan standar deviasi gabungan. Rumusnya adalah:

$$
d=\frac{\bar{X}_{t}-\bar{X}_{c}}{S_{g a b}}
$$

dengan kriteria ukuran efek sebagai berikut.

Efek kecil $\quad: 0,2 \leq d<0,5$

Efek sedang : $0,5 \leq d<0,8$

Efek besar $\quad: d \geq 0,8$

\section{HASIL DAN PEMBAHASAN}

Pada penelitian ini jumlah skripsi cooperative learning yang sesuai dengan tujuan penelitian adalah 44 judul skripsi. Adapun rinciannya sebagai berikut. 
Tabel 1. Effect size skripsi secara keseluruhan

\begin{tabular}{|c|c|c|c|}
\hline No & Kode skripsi & $\operatorname{ES}(d)$ & Kategori \\
\hline 1 & S35 & 1,65 & \multirow{14}{*}{ Efek kecil } \\
\hline 2 & S32 & 1,56 & \\
\hline 3 & S05 & 1,35 & \\
\hline 4 & S15 & 1,34 & \\
\hline 5 & S26 & 1,27 & \\
\hline 6 & S03 & 1,15 & \\
\hline 7 & $\mathrm{~S} 13$ & 1,15 & \\
\hline 8 & $\mathrm{~S} 21$ & 1,13 & \\
\hline 9 & S31 & 1,06 & \\
\hline 10 & $\mathrm{~S} 23$ & 0,99 & \\
\hline 11 & $\mathrm{~S} 12$ & 0,96 & \\
\hline 12 & S29 & 0,94 & \\
\hline 13 & S07 & 0,91 & \\
\hline 14 & S39 & 0,86 & \\
\hline 15 & S27 & 0,73 & \multirow{18}{*}{ Efek sedang } \\
\hline 16 & S41 & 0,73 & \\
\hline 17 & S36 & 0,72 & \\
\hline 18 & S44 & 0,70 & \\
\hline 19 & S17 & 0,66 & \\
\hline 20 & $\mathrm{~S} 02$ & 0,65 & \\
\hline 21 & S24 & 0,64 & \\
\hline 22 & $\mathrm{~S} 20$ & 0,63 & \\
\hline 23 & S34 & 0,63 & \\
\hline 24 & S43 & 0,62 & \\
\hline 25 & S04 & 0,58 & \\
\hline 26 & S01 & 0,56 & \\
\hline 27 & S06 & 0,55 & \\
\hline 28 & S14 & 0,55 & \\
\hline 29 & S33 & 0,55 & \\
\hline 30 & S08 & 0,51 & \\
\hline 31 & S10 & 0,51 & \\
\hline 32 & S09 & 0,50 & \\
\hline 33 & S38 & 0,48 & \multirow{12}{*}{ Efek besar } \\
\hline 34 & S42 & 0,48 & \\
\hline 35 & S16 & 0,47 & \\
\hline 36 & S37 & 0,46 & \\
\hline 37 & S28 & 0,45 & \\
\hline 38 & S30 & 0,45 & \\
\hline 39 & S11 & 0,43 & \\
\hline 40 & S18 & 0,42 & \\
\hline 41 & S40 & 0,38 & \\
\hline 42 & S22 & 0,35 & \\
\hline 43 & S19 & 0,22 & \\
\hline 44 & S25 & 0,20 & \\
\hline \multicolumn{4}{|c|}{$\overline{E S}=0,73$} \\
\hline
\end{tabular}

Hasil data analisis pada tabel 1 menunjukkan bahwa terdapat empat belas skripsi dengan nilai effect size besar, delapan belas skripsi dengan nilai effect size sedang, dan dua belas skripsi dengan nilai effect size kecil. Dari perhitungan diperoleh effect size total 
sebesar 0,73 dalam kategori sedang dan standar deviasi sebesar 0,35. Angka ini memberikan makna bahwa perlakuan cooperative learning dalam pembelajaran matematika mampu meningkatkan prestasi belajar peserta didik pada kelas eksperimen sebesar 0,73 kali dari besar pengaruh kelas kontrol. Hal ini menjelaskan bahwa pembelajaran matematika dengan menggunakan cooperative learning efektif untuk digunakan dalam proses pembelajaran di kelas sehingga cooperative learning lebih cocok digunakan dalam kelas matematika daripada pembelajaran konvensional.

\section{Tipe Cooperative Learning}

Ada beberapa variasi atau tipe dalam model pembelajaran cooperative learning. Tipe cooperative learning yang telah digunakan dalam penelitian mahasiswa pendidikan matematika dalam meningkatkan prestasi belajar peserta didik sebagai berikut.

Tabel 2. Effect size berdasarkan tipe cooperative learning

\begin{tabular}{clcccc}
\hline No & Tipe cooperative learning & n Skripsi & $\overline{E S}$ & SD & KV \\
\hline 1 & STAD & 8 & 0,73 & 0,41 & 0,56 \\
2 & Make a match & 5 & 0,78 & 0,53 & 0,68 \\
3 & Think pair share & 5 & 0,81 & 0,40 & 0,50 \\
4 & Numbered head together & 4 & 0,79 & 0,36 & 0,46 \\
5 & Course review horay & 2 & 0,85 & 0,42 & 0,50 \\
6 & Example non example & 2 & 0,57 & 0,13 & 0,24 \\
7 & Jigsaw & 2 & 0,64 & 0,01 & 0,02 \\
8 & Snowball throwing & 2 & 0,59 & 0,04 & 0,07 \\
9 & Student facilitator and explaining & 2 & 0,60 & 0,19 & 0,32 \\
10 & Talking stick & 2 & 1,06 & 0,71 & 0,68 \\
11 & Teams games tournament & 2 & 0,69 & 0,43 & 0,63 \\
12 & Two stay two stray & 2 & 0,80 & 0,49 & 0,62 \\
13 & Cooperative script & 1 & 0,48 & - & - \\
14 & Group investigation & 1 & 0,64 & - & - \\
15 & Round club & 1 & 0,94 & - & - \\
16 & Team assisted individualization & 1 & 0,72 & - & - \\
17 & Think talk write & 1 & 0,55 & - & - \\
18 & Time token & 1 & 0,42 & - & - \\
\hline Keterangan: & & & & \\
ES & : rerata effect size & & & & \\
SD & : standar deviasi & & & & \\
KV & : koefisien variasi & & & &
\end{tabular}

Tipe cooperative learning yang paling tinggi pengaruhnya adalah tipe talking stick dengan nilai effect size sebesar 1,06 dalam kategori efek besar. Ada lima tipe cooperative learning yang memberikan efek besar yaitu think pair share, course review horay, talking stick, two stay two stray, dan round club. 
Ada beberapa hal yang mempengaruhi model pembelajaran cooperative learning tipe talking stick mampu menghasilkan kontribusi yang besar pada peningkatan prestasi belajar peserta didik, yaitu:

a. Model cooperative learning tipe talking stick bersifat aktif dan kolaboratif. Penggunaan model pembelajaran cooperative learning tipe talking stick melatih keberanian peserta didik dalam menjawab dan berbicara kepada orang lain. Tipe pembelajaran ini menggunakan tongkat/stick sebagai media bagi peserta didik untuk menjawab pertanyaan (Mukhti, 2016; Subekti, Kartana, \& Utami, 2017). Dalam sesi pembelajaran ini juga menggunakan lagu untuk menggilir tongkat sehingga peserta didik lebih ceria dan semangat dalam belajar. Pengunaan tongkat secara bergiliran mampu merangsang peserta didik untuk bertindak cepat dan tepat sekaligus untuk mengukur kemampuan peserta didik dalam memahami materi pelajaran.

b. Dari dua penelitian skripsi yang menggunakan tipe ini (Mukhti, 2016; Subekti et al., 2017) diperoleh bahwa kedua penelitian ini menggunakan alat peraga sebagai medianya dan materi yang diajarkan adalah bangun ruang sisi datar dan aritmatika sosial. Materi ini adalah materi yang mudah untuk divisualisasikan dalam pembelajaran ke arah yang lebih konkrit seperti alat peraga.

\section{Jenjang Pendidikan}

Jenjang pendidikan merupakan salah satu aspek yang dapat dianalisis dalam penelitian ini yaitu terdiri dari jenjang pendidikan tingkat menengah pertama (SLTP) dan jenjang pendidikan tingkat menengah atas (SLTA).

Tabel 3. Effect size berdasarkan jenjang pendidikan

\begin{tabular}{cccccc}
\hline No & Jenjang pendidikan & n Skripsi & $\overline{E S}$ & SD & KV \\
\hline 1 & SLTP & 35 & 0,76 & 0,36 & 0,47 \\
2 & SLTA & 9 & 0,60 & 0,27 & 0,46 \\
\hline
\end{tabular}

Penerapan cooperative learning terhadap prestasi belajar matematika berdasarkan jenjang pendidikan memberikan pengaruh positif pada peserta didik pada jenjang SLTP. Nilai effect size pada jenjang pendidikan SLTP yaitu sebesar 0,76 dalam kategori sedang. Sedangkan nilai effect size pada jenjang pendidikan SLTA sebesar 0,60 dalam kategori sedang. Jenjang pendidikan SLTP memiliki besar pengaruh tertinggi terhadap prestasi belajar matematika. Temuan ini mengungkapkan bahwa jenjang pendidikan SLTP lebih efektif menggunakan model pembelajaran cooperative learning daripada jenjang pendidikan SLTA. 
Pembelajaran secara berkelompok merupakan ciri khas dari cooperative learning dimana peserta didik berdiskusi mengenai suatu permasalahan untuk mencari penyelesaiannya secara bersama-sama. Peserta didik pada jenjang SLTP cenderung lebih mudah diatur dalam pembelajaran berkelompok daripada peserta didik pada jenjang SLTA yang lebih memilih pembelajaran secara individualistik karena pada tingkat ini mereka ingin lebih menonjolkan kemampuannya masing-masing.

Temuan ini sejalan dengan penelitian Stoner (Stoner, 2004) pada meta analisis keefektifan pembelajaran kooperatif peserta didik sekolah menengah yang menunjukkan hasil positif terhadap prestasi belajar dengan rata-rata effect size yang dihasilkan sebesar 0,135. Hal ini juga sejalan dengan hasil penelitian Johnson (Johnson, Johnson, \& Stanne, 2000) yang menyatakan bahwa pembelajaran kooperatif efektif diterapkan pada jenjang pendidikan menengah dengan nilai effect size yang dihasilkan pada kategori sedang.

\section{Media Pembelajaran}

Media pembelajaran merupakan instrumen yang strategis dalam menentukan keberhasilan proses pembelajaran. Media pembelajaran yang telah digunakan dalam penelitian mahasiswa pendidikan matematika Universitas Pancasakti Tegal dikelompokkan sebagai berikut.

Tabel 4. Effect size berdasarkan media pembelajaran

\begin{tabular}{cccccc}
\hline No & Media pembelajaran & n Skripsi & $\overline{E S}$ & SD & KV \\
\hline 1 & Alat peraga & 19 & 0,75 & 0,36 & 0,47 \\
2 & Aplikasi komputer/website & 6 & 0,79 & 0,39 & 0,50 \\
3 & CD pembelajaran & 3 & 0,69 & 0,35 & 0,51 \\
4 & Musik mozart & 1 & 0,58 & - & - \\
5 & Tanpa media pembelajaran & 15 & 0,70 & 0,36 & 0,52 \\
\hline
\end{tabular}

Aplikasi komputer atau website memberikan efek yang paling tinggi yaitu sebesar 0,79 dalam kategori sedang. Media pembelajaran yang paling konsisten pengaruhnya yaitu alat peraga dengan nilai effect size sebesar 0,75 . Alat peraga, $\mathrm{CD}$ pembelajaran, dan musik mozart juga memberikan pengaruh positif pada proses pembelajaran dengan nilai effect size masing-masing berada dalam kategori sedang. Temuan ini mengungkapkan bahwa media pembelajaran berbantuan aplikasi komputer atau website cocok dipadukan dengan cooperative learning.

Aplikasi komputer atau website yang telah digunakan dalam penelitian mahasiswa yaitu microsoft power point, geogebra, adobe flash, dan quipper school. Media pembelajaran seperti ini membantu peserta didik dalam memahami materi pelajaran melalui bentuk visual yang unik dan bervariasi. Pemanfaatan media pembelajaran berupa 
aplikasi komputer atau website yang dipadukan dengan cooperative learning menjadikan proses pembelajaran lebih bermakna. Kontribusi yang diberikan pada pembelajaran cooperative learning cukup besar dengan menggunakan media pembelajaran berupa aplikasi komputer atau website.

Temuan ini sejalan dengan hasil penelitian Prasetiyo (Prasetiyo et al., 2014) yang menyatakan bahwa media pembelajaran berbantuan komputer mampu meningkatkan prestasi belajar matematika peserta didik dengan nilai effect size yang dihasilkan sebesar 0,79 pada kategori sedang. Hal ini juga sejalan dengan hasil penelitian Tumangkeng (Tumangkeng, Yusmin, \& Hartoyo, 2018) yang menyatakan bahwa penggunaan media elektronik mampu menghasilkan effect size sebesar 0,70 pada kategori sedang.

\section{Materi Pelajaran}

Setiap materi pelajaran mempunyai karakteristik yang berbeda-beda sehingga penggunaan model pembelajaran harus disesuaikan dengan materi yang disampaikan.

Tabel 4. Effect size berdasarkan materi pelajaran

\begin{tabular}{clcccc}
\hline No & Media pembelajaran & n Skripsi & $\overline{E S}$ & SD & KV \\
\hline 1 & Segitiga dan Segiempat (SLTP) & 11 & 0,65 & 0,28 & 0,43 \\
2 & Bangun Ruang Sisi Datar (SLTP) & 8 & 0,85 & 0,48 & 0,56 \\
3 & Aritmatika Sosial (SLTP) & 6 & 0,71 & 0,27 & 0,38 \\
4 & Lingkaran (SLTP) & 5 & 1,07 & 0,46 & 0,43 \\
5 & Himpunan (SLTP) & 3 & 0,57 & 0,26 & 0,45 \\
6 & SPLDV (SLTP) & 2 & 0,67 & 0,05 & 0,07 \\
7 & Statistika (SLTP) & 1 & 0,35 & - & - \\
8 & Statistika (SLTA) & 1 & 0,45 & - & - \\
9 & Trigonometri (SLTA) & 2 & 0,62 & 0,16 & 0,26 \\
10 & Turunan Fungsi Aljabar (SLTA) & 2 & 0,55 & 0,13 & 0,25 \\
11 & Aturan Pencacahan (SLTA) & 1 & 1,06 & - & - \\
12 & Ruang Dimensi Tiga (SLTA) & 1 & 0,91 & - & - \\
13 & Transformasi Geometri (SLTA) & 1 & 0,42 & - & - \\
\hline
\end{tabular}

Lingkaran adalah materi yang memberikan pengaruh positif dan berkontribusi besar terhadap peningkatan prestasi belajar peserta didik. Nilai effect size pada materi lingkaran yaitu sebesar 1,07 dalam kategori efek besar. Materi pelajaran yang paling sering diterapkan dalam penelitian mahasiswa adalah materi segitiga dan segiempat tetapi hanya memberikan effect size rata-rata sebesar 0,65.

Lingkaran adalah bagian dari ilmu geometri. Materi lingkaran merupakan materi yang memiliki sifat visual dan dapat dibawa ke arah yang lebih konkret untuk diaplikasikan dalam pembelajaran. Oleh karena itu peserta didik lebih mudah untuk memahami hal-hal yang bersifat konkret dibandingkan yang bersifat abstrak, sehingga peserta didik lebih mudah memahami materi lingkaran apalagi dalam pembelajaran disertai 
dengan media pembelajaran dalam bentuk visual. Penggunaan materi lingkaran pada pembelajaran cooperative learning mampu memberikan kontribusi besar dan konsisten terhadap peningkatan prestasi belajar matematika peserta didik.

Temuan ini sejalan dengan hasil penelitian Capar \& Tarim (Capar \& Tarim, 2015) yang menyatakan bahwa sub bidang geometri efektif diterapkan pada pembelajaran kooperatif dengan nilai effect size yang dihasilkan sebesar 0,67 pada kategori sedang. Hal ini juga sejalan dengan hasil penelitian Prasetiyo (Prasetiyo et al., 2014) yang menyatakan bahwa penerapan cooperative learning yang menghasilkan nilai effect size paling besar dan konsisten adalah yang diterapkan pada saat mengajarkan materi pada pokok bahasan geometri. Lingkaran adalah bagian dari ilmu geometri. Materi lingkaran merupakan materi yang memiliki sifat visual dan dapat dibawa ke arah yang lebih konkret untuk diaplikasikan dalam pembelajaran. Oleh karena itu peserta didik lebih mudah untuk memahami hal-hal yang bersifat konkret dibandingkan yang bersifat abstrak, sehingga peserta didik lebih mudah memahami materi lingkaran apalagi dalam pembelajaran disertai dengan media pembelajaran dalam bentuk visual.

\section{KESIMPULAN}

Berdasarkan temuan dan hasil analisis data yang diperoleh, maka dapat disimpulkan sebagai berikut:

1. Secara keseluruhan besar pengaruh (effect size) cooperative learning terhadap prestasi belajar matematika yaitu sebesar 0,73 yang termasuk dalam kategori sedang. Hal tersebut menunjukkan bahwa model pembelajaran cooperative learning memberikan pengaruh yang lebih efektif dan layak digunakan dalam pembelajaran matematika. Model pembelajaran cooperative learning merupakan alternatif pembelajaran untuk meningkatkan prestasi belajar matematika.

2. Berdasarkan tipe cooperative learning, dari delapan belas tipe yang digunakan dalam penelitian mahasiswa, yang paling besar pengaruhnya adalah cooperative learning tipe talking stick dengan nilai effect size yang dihasilkan sebesar 1,06 dalam kategori besar. Selain tipe talking stick ada beberapa tipe cooperative learning yang juga menghasilkan nilai effect size dalam kategori efek besar diantaranya think pair share, course review horay, two stay two stray, dan round club.

3. Besar pengaruh penerapan cooperative learning terhadap prestasi belajar matematika berdasarkan jenjang pendidikan menunjukkan bahwa pada jenjang SLTP lebih tinggi nilai effect size yang dihasilkan dari jenjang SLTA yaitu sebesar 0,76 dalam kategori 
sedang. Pembelajaran cooperative learning lebih efektif diterapkan pada jenjang SLTP karena menghasilkan nilai effect size yang lebih tinggi.

4. Besar pengaruh penerapan cooperative learning terhadap prestasi belajar berdasarkan media pembelajaran menunjukkan bahwa penggunaan aplikasi komputer atau website menghasilkan nilai effect size sebesar 0,79 dalam kategori sedang. Hal ini menunjukkan bahwa penggunaan media pembelajaran berupa aplikasi komputer atau website lebih efektif digunakan dalam pembelajaran cooperative learning untuk meningkatkan prestasi belajar matematika.

5. Besar pengaruh penerapan cooperative learning terhadap prestasi belajar berdasarkan materi pelajaran menunjukkan hasil yang positif pada materi lingkaran dengan nilai effect size yang dihasilkan sebesar 1,07 dalam kategori besar. Hal ini menunjukkan bahwa materi lingkaran efektif digunakan dalam cooperative learning untuk meningkatkan prestasi belajar matematika. Selain lingkaran ada beberapa materi yang juga menghasilkan nilai effect size dalam kategori besar diantaranya bangun ruang sisi datar, aturan pencacahan, dan ruang dimensi tiga.

\section{REFERENSI}

Anadiroh, M. (2019). Studi Meta-Analisis Model Pembelajaran Problem Based Learning $(P B L)$. Jakarta: FITK UIN Syarif Hidayatullah Jakarta, Jakarta.

Aslikhah, N. (2015). Meta Analisis Dengan Effect Size Odds Ratio Pada Kasus Pengaruh Terapi B-Blocker Untuk Pasien Gagal Jantung. Skripsi Fakultas Matematika Dan Ilmu Pengetahuan Alam.

Budiman, H., \& Esvigi, I. (2017). Implementasi Strategi Mathematical Habits of Mind (MHM) Berbantuan Multimedia untuk Meningkatkan Kemampuan Berpikir Kritis Siswa. PRISMA, 6(1). https://doi.org/10.35194/jp.v6i1.26

Capar, G., \& Tarim, K. (2015). Efficacy of the Cooperative Learning Method on Mathematics Achievement and Attitude: A Meta-Analysis Research. Educational Sciences: Theory and Practice, 15(2), 553-559.

Chandra, E. (2011). Efektivitas Media Pembelajaran dalam Pembelajaran Biologi (Meta Analisis Terhadap Penelitian Eksperimen dalam Pembelajaran Biologi). Holistik, 12(1).

Eliyah, S., Isnani, I., \& Utami, W. B. (2018). Keefektifan model pembelajaran course review horay berbantuan power point terhadap kepercayaan diri dan prestasi belajar. Jurnal Edukasi Dan Sains Matematika (JES-MAT), 4(2), 131-140.

Glass, G. V, \& Smith, M. L. (2012). Meta-analysis of research on class size and achievement. Educational Evaluation and Policy Analysis, 1(1), 2-16.

Hijrihani, C. P., \& Wutsqa, D. U. (2015). Keefektifan Cooperative Learning Tipe Jigsaw dan STAD Ditinjau dari Prestasi Belajar dan Kepercayaan Diri Siswa. PYTHAGORAS: Jurnal Pendidikan Matematika, 10(1), 1-14.

Isnani, M. S., \& Ambarwati, R. (2011). Keefektifan Metode Think, Pair and Share Dalam Pembelajaran Matematika Berbantuan Cd Interaktif Materi Bangun Ruang Kelas V. Cakrawala: Jurnal Pendidikan, 6(2). 
Johnson, D. W., Johnson, R. T., \& Stanne, M. B. (2000). Cooperative learning methods: A meta-analysis. Minneapolis.

Maskur, R., Sumarno, Rahmawati, Y., Pradana, K., Syazali, M., Septian, A., \& Palupi, E. K. (2020). The effectiveness of problem based learning and aptitude treatment interaction in improving mathematical creative thinking skills on curriculum 2013. European Journal of Educational Research, 9(1), 375-383. https://doi.org/10.12973/eu-jer.9.1.375

Mukhti, G. B. M. (2016). Keefektifan Model Pembelajaran Talking Stick Terhadap Minat dan Prestasi Belajar Matematika. Universitas Pancasakti Tegal.

Nurjanah, S. (2019). Keefektifan Model Pembelajaran Kooperatif Course Review Horay dengan Kerangka Bangun Ruang Terhadap Prestasi Belajar Peserta Didik. Universitas Pancasakti Tegal.

Prasetiyo, A. Y., Yusmin, E., \& Hartoyo, A. (2014). Meta-analisis pengaruh cooperative learning terhadap peningkatan hasil belajar matematika siswa. Jurnal Untan, 1(1), 111.

Rusman. (2016). Model-model pembelajaran: Mengembangkan profesionalisme guru. Rajawali Pers/PT Raja Grafindo Persada.

Septian, A., Darhim, \& Prabawanto, S. (2020). Geogebra in integral areas to improve mathematical representation ability. Journal of Physics: Conference Series, 1613(1), 12035. https://doi.org/10.1088/1742-6596/1613/1/012035

Siagian, R. E. F. (2015). Pengaruh minat dan kebiasaan belajar siswa terhadap prestasi belajar matematika. Formatif: Jurnal Ilmiah Pendidikan MIPA, 2(2).

Situmeang, A. (2016). Penerapan Model Pembelajaran Kooperatif pada Pelajaran Matematika dan Bahasa Indonesia dalam Meningkatkan Hasil Belajar Siswa Kelas 3 SDN 154503 Hutabalang 3. ELEMENTARY SCHOOL JOURNAL PGSD FIP UNIMED, 6(2), 55-59.

Stoner, D. A. (2004). The Effects of Cooperative Learning Strategies on Mathematics Achievement Among Middle-grades Students: A Meta-analysis. University of Georgia.

Subekti, I., Kartana, T. J., \& Utami, W. B. (2017). Keefektifan Model Pembelajaran Talking Stick Terhadap Sikap Dan Prestasi Belajar Matematika Pada Materi Aritmatika Sosial. Jurnal Dialektika Program Studi Pendidikan Matematika, 4(2), 43-49.

Sugiyono, D. R. (2015). Statistika untuk Penelitian [Statistic for Research]. In Alfabeta, Bandung (2012.)(in Bahasa Indonesia).

Suwarman, R. F. (2018). Analisis Tingkat Kemampuan Pemahaman Konsep. Jurnal Prisma, VII(2), 227-237.

Tumangkeng, Y. W., Yusmin, E., \& Hartoyo, A. (2018). Meta-Analisis Pengaruh Media Pembelajaran Terhadap Hasil Belajar Matematika Siswa. Jurnal Pendidikan Dan Pembelajaran Khatulistiwa, 7(6). 